\title{
Occipital nerve stimulation and deep brain stimulation for refractory cluster headache: a prospective analysis of efficacy over time
}

\author{
Juan Ángel Aibar-Durán, MD, ${ }^{1}$ María Jesús Álvarez Holzapfel, MD, ${ }^{1}$ \\ Rodrigo Rodríguez Rodríguez, MD, ${ }^{1}$ Robert Belvis Nieto, MD, ${ }^{2}$ Carles Roig Arnall, MD, ${ }^{2}$ and \\ Joan Molet Teixido, PhD'
}

Departments of ${ }^{1}$ Neurosurgery and ${ }^{2}$ Neurology, Santa Creu i Sant Pau Hospital, Barcelona, Spain

\begin{abstract}
OBJECTIVE Occipital nerve stimulation (ONS) and deep brain stimulation (DBS) are widely used surgical treatments for chronic refractory cluster headache $(\mathrm{CH})$. However, there is little literature regarding long-term follow-up of these treatments.
\end{abstract}

METHODS The authors describe two prospective cohorts of patients with refractory $\mathrm{CH}$ treated with ONS and DBS and compare preoperative to postoperative status at 6 and 12 months after the surgery and at final follow-up. Efficacy analysis using objective and subjective variables is reported, as well as medication reduction and complications.

RESULTS The ONS group consisted of 13 men and 4 women, with a median age of 44 years (range 31-61 years). The median number of attacks per week (NAw) before surgery was 28 (range 7-70), and the median follow-up duration was 48 months. The DBS group comprised 5 men and 2 women, with a median age of 50 years (range 29-64 years). The median NAw before surgery was 56 (range 14-140), and the median follow-up was 36 months. The NAw and visual analog scale score were significantly reduced for the ONS and DBS groups after surgery. However, while all the patients from the DBS group were considered responders at final follow-up, with more than $85 \%$ being satisfied with the treatment, approximately $29 \%$ of initial responders to ONS became resistant by the final follow-up $(p=0.0253)$.

CONCLUSIONS ONS is initially effective as a treatment for refractory $\mathrm{CH}$, although a trend toward loss of efficacy was observed. No clear predictors of good clinical response were found in the present study. Conversely, DBS appears to be effective and provide a more stable clinical response over time with an acceptable rate of surgical complications.

https://thejns.org/doi/abs/10.3171/2019.11.JNS192042

KEYWORDS cluster headache; occipital nerve stimulation; deep brain stimulation; functional neurosurgery; pain

A MONG primary headache syndromes, cluster headache $(\mathrm{CH})$ is a disabling condition that primarily affects young people and for which pharmacological treatment is first indicated. ${ }^{1,2,9}$ According to the 3rd Edition of the International Classification of Headache Disorders (ICHD-3), $\mathrm{CH}$ is characterized by unilateral headache attacks ranging in duration from 15 to 180 minutes, frequently accompanied by parasympathetic ipsilateral symptoms that are essential to understanding $\mathrm{CH}$ pathophysiology. ${ }^{6,8-10}$ Approximately $10 \%$ of patients have chronic $\mathrm{CH}$, defined as recurrent attacks with no pain-free periods longer than 1 month for a minimum of 1 year, and $10 \%$ of patients with chronic $\mathrm{CH}$ are refractory to phar- macological treatment. ${ }^{8,17}$ Surgical treatment is indicated for highly symptomatic patients (despite suitable pharmacological treatment) and for patients who poorly tolerate pharmacological treatment., ${ }^{9,10,21}$ While good clinical responses to occipital nerve stimulation (ONS) and deep brain stimulation (DBS) have been reported, ${ }^{2-4,7,14,18}$ the long-term efficacy of these treatments has not been widely studied.

We conducted a retrospective analysis of prospectively collected data of two cohorts of patients with refractory chronic $\mathrm{CH}$ treated with ONS and DBS between 2006 and 2018. Analysis of the efficacy of both treatments and the associated complications were reported. We also conduct-

ABBREVIATIONS $\mathrm{CH}=$ cluster headache; $\mathrm{DBS}=$ deep brain stimulation; ICHD = International Classification of Headache Disorders; IPG = implantable pulse generator; $\mathrm{NAw}=$ number of attacks per week; ONS = occipital nerve stimulation; OR = odds ratio; ORR = overall response rate; PRF = pulsed radiofrequency; RFA = radiofrequency ablation; SPG = sphenopalatine ganglion; SUNCT = short-lasting unilateral neuralgiform headache with conjunctival injection and tearing; VAS = visual analog scale. SUBMITTED July 27, 2019. ACCEPTED November 12, 2019.

INCLUDE WHEN CITING Published online January 17, 2020; DOI: 10.3171/2019.11.JNS192042. 
ed a multivariate analysis of the data for the ONS group to identify possible predictors of a good response by the final follow-up.

\section{Methods \\ Study Sample}

Patients referred by a general physician or neurologist from other hospitals were initially evaluated by a multidisciplinary headache committee formed by a senior neurologist trained in headache diagnosis and treatment, 2 senior functional neurosurgeons, 1 anesthesiologist trained in pain treatment, 1 neuroradiologist, 1 psychiatrist, and 1 neuropsychologist. The patients were diagnosed according to ICHD-3 criteria, with $\mathrm{CH}$ considered refractory if the patient had at least 3 severe attacks per week, despite at least 3 consecutive trials of suitable preventive treatments. A normal brain MR image was available for all patients.

As part of the headache committee standard practice, patients with refractory $\mathrm{CH}$ who are unresponsive to suitable pharmacological treatment undergo radiofrequency ablation (RFA) of the sphenopalatine ganglion (SPG), and some patients also undergo occipital nerve block, which usually provide only temporary relief of their symptoms. These patients are evaluated as candidates for further invasive therapies, namely ONS and/or DBS. Because the level of evidence supporting both therapies is low to medium, we first indicate ONS because it is less invasive. If ONS is not effective, the implant is removed, and the headache committee reevaluates the patient for DBS. Those patients who are not responsive to ONS are evaluated again by the multidisciplinary committee and DBS is proposed, considering the patient's willingness and the impact of the headache on the patient's life. Generally speaking, excluded as candidates for ONS are patients with major comorbidities who cannot tolerate general anesthesia or who have previously undergone cervical surgery; excluded as candidates for DBS are patients with cerebral lesions on MRI that may interfere with deep electrode trajectories; and excluded as candidates for either ONS or DBS are patients with severe psychiatric or cognitive disorders diagnosed prior to $\mathrm{CH}$ commencement, because they might not be capable of understanding or managing the device.

Patients with refractory $\mathrm{CH}$ included in the present study were between 18 and 70 years old and were considered by our headache committee to be suitable candidates for ONS and/or DBS treatment between 2006 and 2018. Included were 17 patients treated with ONS (ONS group) and 7 patients treated with DBS (DBS group). All participants gave their informed consent for participation in the present study.

\section{Variables and Definitions}

For the purpose of this study, data regarding initial headache characteristics and severity, psychiatric assessment details, and demographic data were recorded for each patient. Drug intake at the time of the operation was also taken into account, with significant drug reduction, for both acute attacks and prophylaxis, defined as a reduction of at least $30 \%$.
The main objective of the study was to assess the efficacy of ONS and DBS over time, measured in terms of impact on headache severity. To assess headache severity, four variables were evaluated for both groups: as objective variables, the number of attacks per week (NAw) and overall response rate (ORR), defined as a reduction of at least $50 \%$ in attack frequency; and as subjective variables, mean visual analog scale (VAS) pain score for each attack and loss of treatment efficacy, defined as the moment the patient perceived headache severity to be similar to that experienced before ONS or DBS treatment. NAw and VAS were measured before surgery, 6 and 12 months after surgery, and at final follow-up. ORR was measured 6 and 12 months after surgery and at final follow-up.

\section{Surgical Technique}

Patients treated with ONS underwent operations under general anesthesia, in the prone position, with the head fixed by a radiolucent frame to allow clear radiological control in the anteroposterior view. A midline linear incision was performed $1 \mathrm{~cm}$ below the inion. Following subcutaneous tissue dissection, 2 Tuohy needles were inserted, one on each side, just over the muscular fascia and pointing at the mastoid process. The octopolar electrodes were fixated to the fascia and were then connected to an implantable pulse generator (IPG) implanted in the upper part of the right buttock (Fig. 1).

In this study, all patients underwent straight ONS implantation without any previous trial period. Previous to the present study, our team had performed some ONS implantations using a trial period, but decided not to follow this procedure for two main reasons. First, a real trial period would require the patient to collaborate during the ONS implantation, that is, to be awake during the surgery. The procedure was painful and uncomfortable for the patient despite use of local anesthesia, and therefore it was not reliable for the surgeon. Second, the neuromodulation effect of the ONS is expected to fully appear at 3-6 months. We believe this is a very long period for the ONS system to be in a trial period given the high risk of infection.

DBS was performed with the patient sedated and under local anesthesia and using a Leksell stereotactic frame. The DBS electrodes were implanted bilaterally in the posterior hypothalamic area using the following coordinates: $x= \pm 2, y=-3$, and $z=-5$. The fact that the patient could easily be awakened during the procedure allowed us to detect possible undesirable hypothalamic or peri-hypothalamic effects and so correct the stimulation parameters and electrode position. Two of those effects are diplopia and patient-reported nonspecific dizziness. In the last year we have used directional lead stimulation to reduce electrical field spread beyond the region of interest. A CT scan was routinely performed after the intervention. This CT scan was contrasted with the preoperative MRI scan to confirm correct electrode location. Finally, the patient was transferred back to the operating room for the IPG implantation (Fig. 2).

\section{Statistical Analysis}

Categorical variables were expressed as frequencies 

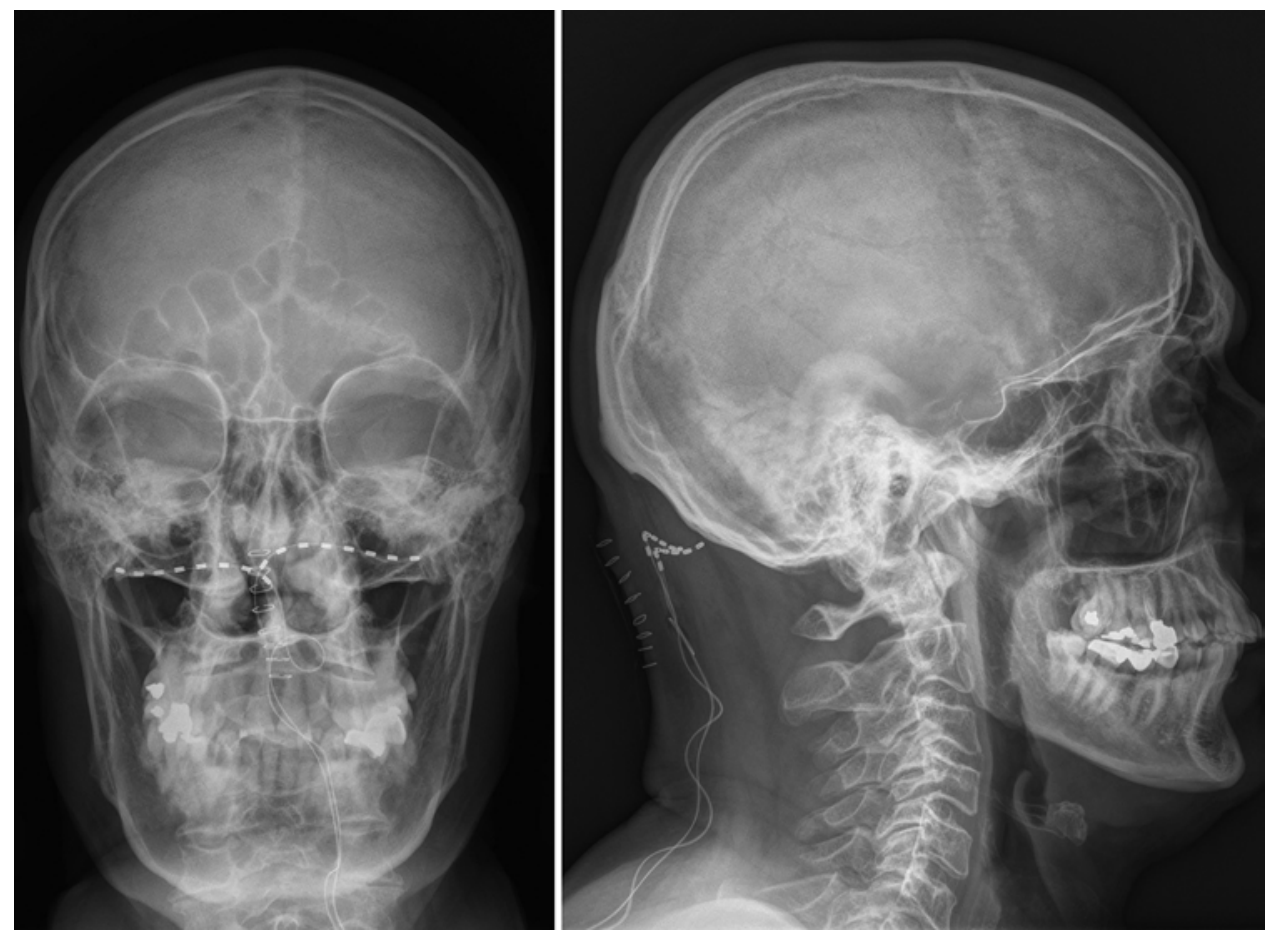

FIG. 1. Skull radiographs of an ONS electrode covering the area of the greater occipital nerve at C1-2.

and percentages, whereas quantitative variables were expressed as medians and ranges. The results were analyzed using the Fisher exact test for categorical variables and the Mann-Whitney U-test for quantitative variables. The Wilcoxon signed-rank test and the McNemar test were used for analyses of paired data. Multivariate analysis was used to determine good clinical response predictors in patients treated with ONS. Differences were considered to be statistically significant for $\mathrm{p}$ values $<0.05$.

\section{Results}

\section{ONS and DBS Patient Characteristics}

Table 1 summarizes the baseline characteristics for
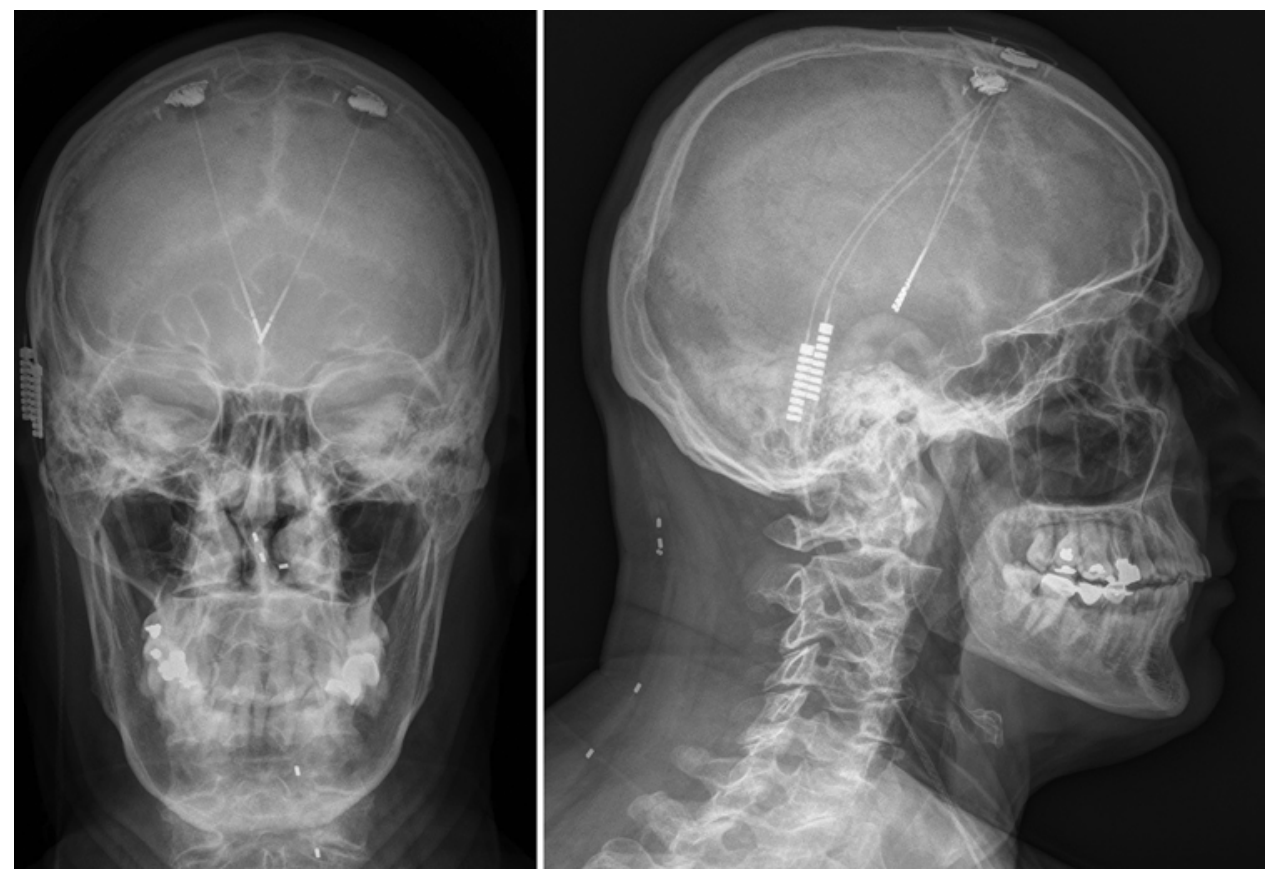

FIG. 2. Skull radiographs of DBS electrodes placed in the posterior hypothalamic region. 
TABLE 1. Descriptive statistics of baseline characteristics for the ONS and DBS groups

\begin{tabular}{lcc}
\hline \multicolumn{1}{c}{ Characteristics } & $\begin{array}{c}\text { ONS Group } \\
(\mathrm{n}=17)\end{array}$ & $\begin{array}{c}\text { DBS Group } \\
(\mathrm{n}=7)\end{array}$ \\
\hline Sex & & \\
\hline $\mathrm{F}$ & 13 & 5 \\
\hline $\mathrm{M}$ & $44(31-61)$ & $50(29-64)$ \\
\hline Median age (range), yrs & & \\
\hline CH side & 3 & 1 \\
\hline Bilat & 7 & 3 \\
\hline Rt & 7 & 3 \\
\hline Lt & $28(7-70)$ & $56(14-140)$ \\
\hline Median NAw (range) & $9(6-10)$ & $8(5-10)$ \\
\hline Median VAS score (range) & & \\
\hline Previous mild psychiatric disorder & 2 & 0 \\
\hline Yes & 15 & 7 \\
\hline No & & \\
\hline CH type & 5 & 0 \\
\hline Episodic & 12 & 7 \\
\hline Chronic & $108(36-396)$ & $54(47-120)$ \\
\hline Median mos w/ CH symptoms (range) & 0 & 7 \\
\hline No. w/ previous ONS & & \\
\hline
\end{tabular}

Nonparametric statistics (median) were used as a more reliable measure of central tendency in small series. both the ONS and DBS groups. The ONS group $(n=17)$ included 13 men (76\%) and 4 women (24\%), with a median age of 44 years old. There was no preference for $\mathrm{CH}$ side. The median NAw before surgery was 28 and median follow-up was 48 months.

The DBS group $(\mathrm{n}=7)$ included 5 men $(71 \%)$ and 2 women (29\%), with a median age of 50 years. All 7 patients in the DBS group had previously undergone ONS, with partial or no relief of symptoms. The median NAw before surgery was 56 and median follow-up was 36 months. It is worth noting that the preoperative NAw for the DBS group was much higher than for the ONS group, as shown in Table 1.

Table 2 shows postsurgical results over the follow-up period for both ONS and DBS group patients for NAw after surgery, VAS after surgery, ORR, loss of efficacy, medication reduction, and complications.

\section{NAw and VAS}

The decrease in NAw and VAS score (recorded before surgery, 6 and 12 months after surgery, and at final followup) was statistically significant when comparing the presurgical to the postsurgical status for both the ONS and DBS groups (Table 2). This result suggests an effect of the ONS and DBS treatment higher than would be expected by chance.

Nonetheless, the NAw and VAS values behaved differently in the 2 groups: for the ONS group, the maximum effect was observed 6 months after surgery, after which the benefit appeared to decrease rapidly until a return to a situation similar to the preoperative status (Fig. 3). For the DBS group, however, despite a small decline in the initial

TABLE 2. Postsurgical results for the ONS and DBS groups

\begin{tabular}{|c|c|c|}
\hline Characteristic & ONS Group $(n=17)$ & DBS Group ( $\mathrm{n}=7$ ) \\
\hline $\begin{array}{l}\text { Median follow-up } \\
\text { (range), mos }\end{array}$ & $48(24-144)$ & $36(6-156)$ \\
\hline \multicolumn{3}{|l|}{ Median NAw, $n$} \\
\hline At 6 mos & 7 & 14 \\
\hline At $12 \mathrm{mos}$ & 21 & 7 \\
\hline At final follow-up & 21 & 14 \\
\hline \multicolumn{3}{|l|}{ Median VAS score, $n$} \\
\hline At 6 mos & 5 & 4 \\
\hline At $12 \mathrm{mos}$ & 8 & 3 \\
\hline At final follow-up & 8 & 4 \\
\hline \multicolumn{3}{|l|}{ ORR, n } \\
\hline At 6 mos & 12 & 7 \\
\hline At 12 mos & 7 & 7 \\
\hline At final follow-up & 7 & 7 \\
\hline Loss of efficacy & $\begin{array}{l}9 \text { patients were unsatisfied } \sim 15 \text { mos after } \\
\text { surgery \& requested implant removal }\end{array}$ & 1 patient was unsatisfied \\
\hline Medication & $\begin{array}{l}\text { No significant reduction in prophylactic medi- } \\
\text { cation in any patient }\end{array}$ & $\begin{array}{l}\text { Significant reduction in prophylactic } \\
\text { medication in } 3 \text { patients }\end{array}$ \\
\hline Complications & $\begin{array}{l}6 \text { cases of paresthesia, } 1 \text { removal due to } \\
\text { infection, } 1 \text { removal due to electrode } \\
\text { displacement }\end{array}$ & $\begin{array}{l}1 \text { reoperation due to electrode } \\
\text { displacement }\end{array}$ \\
\hline
\end{tabular}



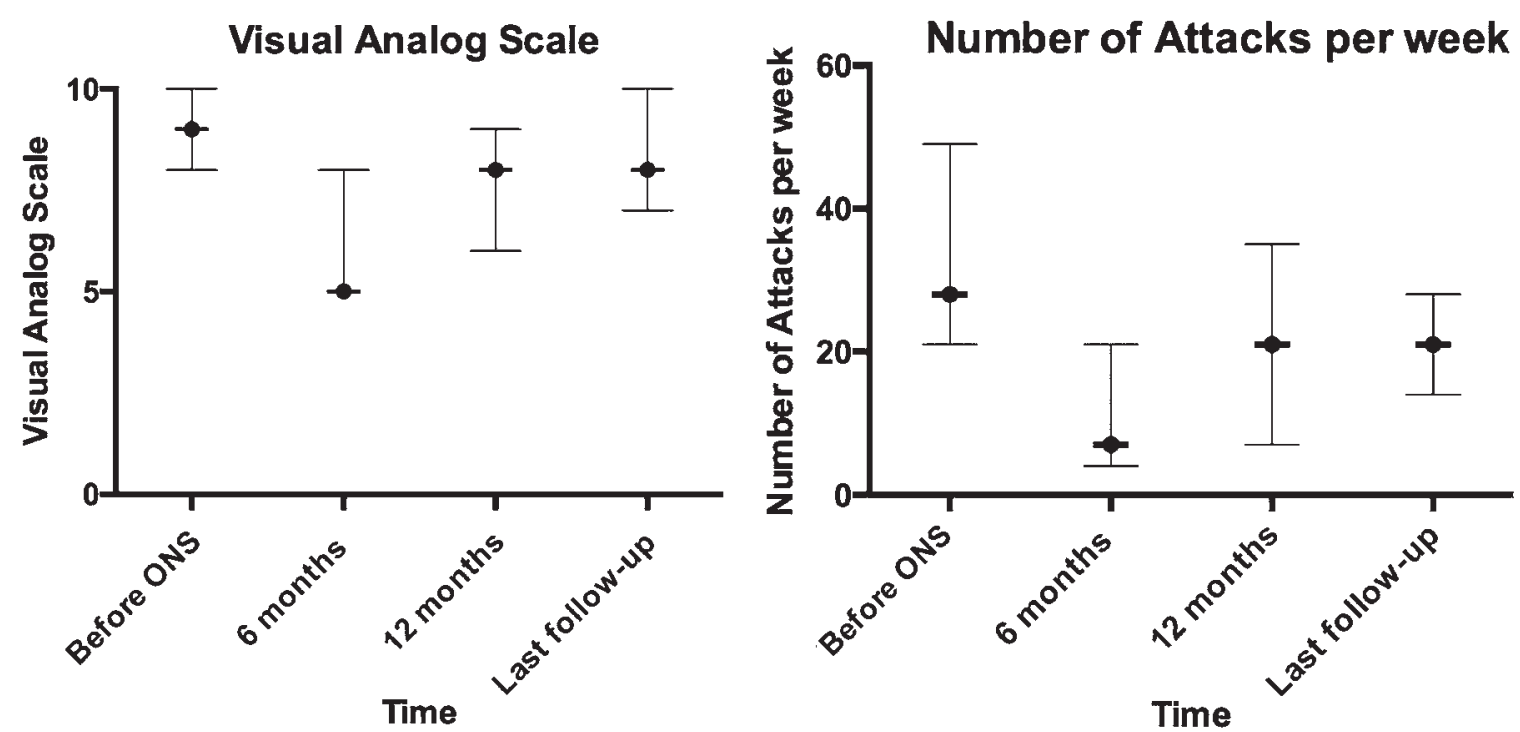

FIG. 3. Evolution of VAS scores (left) and NAw (right) in the ONS group. Medians and ranges are shown.

improvement, an overall positive impact seemed to be apparent by final follow-up (Fig. 4).

\section{Overall Response Rate}

For the ONS group, the ORR at 6 months after surgery was $70.59 \%$, but it decreased by a statistically significant degree to $41.18 \%$ by final follow-up ( $p=0.0253$ ), whereas for the DBS group, the ORR was maintained at $100 \%$ throughout the entire postsurgical period (Table 2). Notably, although the overall response rate by final followup was $41.18 \%, 12$ patients $(70.58 \%)$ appeared to be unsatisfied with the therapy, which should raise the question about the global and true efficacy of ONS in this group of patients (see below and Table 3).

Regarding the use of medication, both groups reduced triptan intake in proportion to the reduction in NAw. How- ever, while no significantly different reduction in prophylactic medication was observed in the ONS group, in the DBS groups 3 patients significantly reduced their intake of prophylactic medication (Table 2).

\section{Loss of Efficacy and Complications}

In the ONS group, differences were found between patient satisfaction and response to therapy. Table 3 shows the cumulative frequency distribution of patients with ONS by the final follow-up. A mismatch was found between patients' satisfaction and their response to therapy, i.e., although 7 patients were responders $(41.18 \%)$ by the final follow-up, 12 (70.6\%) reported to be unsatisfied with ONS. In addition, the implant was removed at the request of 11 of these 12 patients ( $64.7 \%$ of the cohort) after a median of 15 months. Interestingly, 3 of those patients had
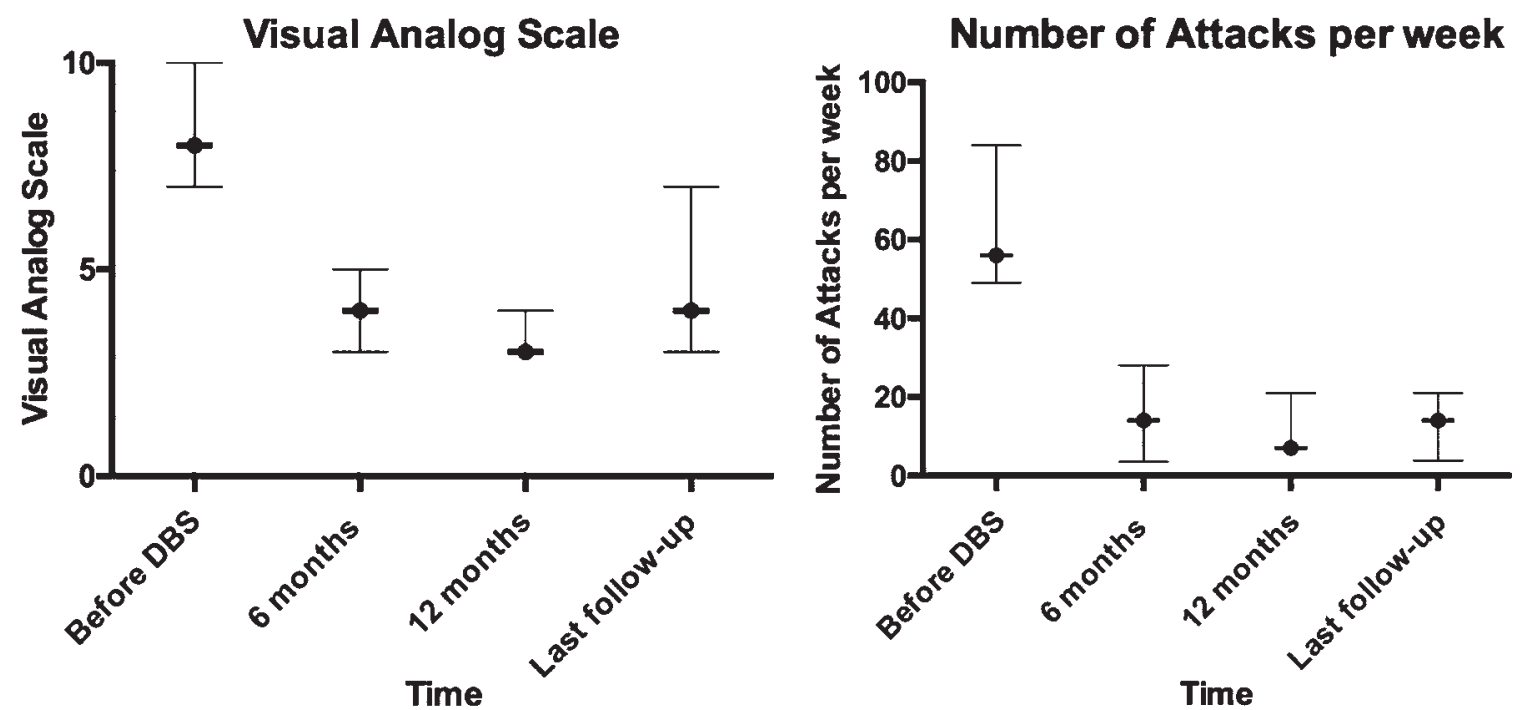

FIG. 4. Evolution of VAS scores (left) and NAw (right) in the DBS group. Medians and ranges are shown. 
TABLE 3. Contingency table showing the cumulative frequency distribution of patients treated with ONS regarding satisfaction and response to the therapy

\begin{tabular}{lccc}
\hline & Satisfied & Unsatisfied & Total \\
\hline Responder & 4 & 3 & 7 \\
\hline Nonresponder & 1 & 9 & 10 \\
\hline Total & 5 & 12 & 17 \\
\hline
\end{tabular}

The data presented correspond to the final follow-up.

previously been classified as responders by the researchers. In contrast, we registered 1 patient who, despite being a nonresponder, did not ask for ONS removal as he felt the intensity of each cluster attack had improved. This mismatch between clinical scales and the patient's perception may be explained by the own patient's expectations about the treatment's efficacy, the continuous ambulatory visits to check and/or modify the system's parameters, the uncomfortable occipital paresthesia, or the IPG replacement surgeries that may give some patients the feeling that the treatment is not worthy.

Six patients (35.3\% of the cohort) reported uncomfortable occipital paresthesia during stimulation, in 1 case even becoming painful. This sensation was more frequent with tonic stimulation and tended to ameliorate with highfrequency stimulation. Two patients had to undergo reoperations, one because of wound infection and the other because of implant displacement. No postsurgical neurological deficits, hemorrhagic complications, or deaths were reported for this group (Table 2).

In the DBS group, at 12 months 1 patient believed that the treatment was not efficacious, although the global reduction in attack frequency was $>50 \%$. This patient was considered a responder but was unsatisfied with the treatment. Another patient had to undergo a reoperation to reposition the electrode (the top part had displaced slightly into the third ventricle). No postsurgical hemorrhagic complications, neurological deficits, or deaths were recorded for this group (Table 2).

Multivariate analysis was used to determine possible predictors of a sustained satisfactory response to the ONS. Patients with a good clinical response at final follow-up were selected for retrospective analysis and controlled for the 7 variables believed to influence the ORR (Table 4). Excluded from the analysis were patients with previously diagnosed psychiatric disorders, given the small number of patients associated with this variable. No statistically significant differences were found for any of the analyzed variables.

\section{Discussion}

Surgical options for $\mathrm{CH}$ are 1) RFA or pulsed radiofrequency (PRF) of the SPG, 2) ONS, or 3) DBS.,21 Our group previously published a descriptive study of a cohort of 37 patients with chronic refractory $\mathrm{CH}$ treated with RFA and PRF of the SPG, which showed that these treatments are effective in reducing the number of $\mathrm{CH}$ attacks, albeit only temporarily. ${ }^{19}$ For patients who fail to respond to those treatments, ONS is indicated as the next logical
TABLE 4. Multivariate logistic regression analysis of the ORR at final follow-up

\begin{tabular}{lccc}
\hline \multicolumn{1}{c}{ Variable } & OR & $p$ Value & $95 \% \mathrm{Cl}$ \\
\hline Age & 1.04 & 0.598 & $0.9-1.20$ \\
\hline Sex & 2.86 & 0.544 & $0.08-92.69$ \\
\hline Tonic vs high-frequency stimulation & 6.40 & 0.233 & $0.30-135.46$ \\
\hline CH type & 5.33 & 0.344 & $0.17-171.76$ \\
\hline Mos w/ CH before ONS & 1.00 & 0.969 & $0.84-1.20$ \\
\hline NAw before ONS & 1.05 & 0.188 & $0.98-1.12$ \\
\hline Initial effectiveness of SPG stimulation & 4.20 & 0.450 & $0.10-174.42$ \\
\hline
\end{tabular}

$\mathrm{Cl}=$ confidence interval.

step. If response to ONS is poor, the implant is removed and DBS is implemented. In our hospital between 2006 and 2018, a total of 17 patients and 7 patients were treated with ONS and DBS, respectively.

\section{Long-Term Efficacy of ONS}

The literature regarding the efficacy of ONS is highly heterogeneous and mostly comprises descriptive studies. Magis et al., ${ }^{13}$ in a study of 15 patients operated on between 2005 and 2009, reported that 10 patients had an ORR of $90 \%$ at final follow-up at 71 months. Miller et al. ${ }^{16}$ in a cohort of 51 patients with a mean follow-up of 39.17 months, concluded that the ONS was a safe and efficacious treatment for refractory $\mathrm{CH}$. Leone et al., ${ }^{12}$ in a study of 35 patients with refractory $\mathrm{CH}$ treated with ONS and followed-up on average for 6.1 years, reported that while one-third of patients were nonresponders at final followup, half of that subgroup had initially responded well to treatment. Our findings regarding ONS are similar. Maximum VAS and NAw reductions were observed 6 months after surgery, although the benefit tended to decrease over time. This reduction in benefit was also observed in comparing the ORR for the first and final postoperative visits, as $29 \%$ of initial responders developed tolerance to the treatment.

The correspondence of a patient to a responder or nonresponder group differed from the patient's own report of treatment efficacy, as 3 of the patients who eventually underwent explantation had been rated as responders by the investigators.

Finally, the logistic regression analysis revealed no clear predictors of maintained clinical response for ONS. This finding contradicts Miller et al., ${ }^{15}$ who in a recent analysis of a group of 100 patients with chronic migraine, chronic $\mathrm{CH}$, and short-lasting unilateral neuralgiform headache with conjunctival injection and tearing (SUNCT) investigating predictors, reported that SUNCT and prior response to occipital nerve block were associated with a good clinical response to ONS. Wilbrink et al. ${ }^{22}$ are currently analyzing preliminary data from an ongoing randomized double-blind trial that might clarify the real effect of ONS on $\mathrm{CH}$.

We would like to note that, as shown in Table 4, the good response to ONS was not related to the preoperative NAw (odds ratio $[\mathrm{OR}] 1.05, \mathrm{p}=0.188$ ). Therefore, no con- 
clusions can be made as to whether patients with more severe headaches are better or worse responders to the ONS. Larger series are necessary for this to be clarified.

\section{Long-Term Efficacy of DBS}

DBS is the most invasive treatment for $\mathrm{CH}$, which is why it is the last option offered to our patients. Reported experiences of this treatment are scarce, with most of the published literature consisting of case reports and case series. Treatment efficacy and follow-up periods vary in existing studies. ORR and mean follow-up duration reported to date are as follows: Leone et al., ${ }^{11} 70 \%$ after 8.7 years; Fontaine et al., ${ }^{5} 50 \%$ after 14.6 months; and SeijoFernandez et al., ${ }^{20} 100 \%$ after 61.3 months. We found a maintained ORR of $100 \%$ at follow-up after 52 months, with just 1 of our 7 patients reporting being unsatisfied with the treatment, despite being a responder.

In patient series in which nonresponders are reported, bilateral episodes of $\mathrm{CH}$ have been identified as a poor response predictor for DBS. ${ }^{11}$ Half of the nonresponders in the study by Fontaine et al. ${ }^{5}$ had bilateral $\mathrm{CH}$; the same author found no differences in mild electrode misplacement (compared with preoperative coordinate planning) between responders and nonresponders, concluding that mechanisms other than electrode misplacement were related to treatment failure. Seijo-Fernandez et al. ${ }^{20}$ suggested that the effect of DBS may be related to stimulation of tracts passing through the posterior hypothalamus (dorsal longitudinal and mamillotegmental fasciculi) rather than proper stimulation of the hypothalamic nucleus.

To summarize, the results of the present study show that, although ONS appears to be initially effective, some patients become tolerant to the therapy. Which patients are at risk for this bad clinical result remains to be determined in larger patient series. Conversely, DBS seems to offer an effective and durable response for these patients. A very interesting observation would be that the patient's perception of efficacy and the objective result measured by clinical scales may sometimes differ, making it necessary to record both variables. Given the present results, our team is now considering offering DBS as the first surgical treatment for $\mathrm{CH}$; however, because of the lack of evidence, it is very difficult to know which patients would respond to DBS rather to ONS. Currently, we tend to offer DBS to young patients $(<40-45$ years old) with severe headaches (>30-40 attacks per week) and who do not have any previous psychiatric disorder. We understand and believe that DBS is a more definitive treatment for $\mathrm{CH}$, but we also know that the risk of potentially severe complications using this technique is also higher.

\section{Study Limitations}

The main limitations of the present study were the small population analyzed and the lack of a control group.

\section{Conclusions}

While ONS is initially effective in patients with refractory $\mathrm{CH}$, with maximum benefit achieved at 6 months after surgery, a trend toward loss of efficacy over time may become evident. DBS efficacy, in contrast, appears to be sustained over a follow-up period of approximately 4 years. In this study, no clear predictors of good clinical response for ONS were found.

\section{Acknowledgments}

Our thanks to Dr. Ignasi Gich and the biostatics department for reviewing the statistical analysis of the manuscript.

\section{References}

1. Abu Bakar N, Tanprawate S, Lambru G, Torkamani M, Jahanshahi M, Matharu M: Quality of life in primary headache disorders: a review. Cephalalgia 36:67-91, 2016

2. Burns B, Watkins L, Goadsby PJ: Treatment of intractable chronic cluster headache by occipital nerve stimulation in 14 patients. Neurology 72:341-345, 2009

3. Burns B, Watkins L, Goadsby PJ: Treatment of medically intractable cluster headache by occipital nerve stimulation: long-term follow-up of eight patients. Lancet 369:1099-1106, 2007

4. Fontaine D, Christophe Sol J, Raoul S, Fabre N, Geraud G, Magne C, et al: Treatment of refractory chronic cluster headache by chronic occipital nerve stimulation. Cephalalgia 31:1101-1105, 2011

5. Fontaine D, Lanteri-Minet M, Ouchchane L, Lazorthes Y, Mertens P, Blond S, et al: Anatomical location of effective deep brain stimulation electrodes in chronic cluster headache. Brain 133:1214-1223, 2010

6. Goadsby PJ: Pathophysiology of cluster headache: a trigeminal autonomic cephalgia. Lancet Neurol 1:251-257, 2002

7. Gooriah R, Buture A, Ahmed F: Evidence-based treatments for cluster headache. Ther Clin Risk Manag 11:1687-1696, 2015

8. Headache Classification Committee of the International Headache Society (IHS): The International Classification of Headache Disorders: 3rd edition. Cephalalgia 38:1-211, 2018

9. Hoffmann J, May A: Diagnosis, pathophysiology, and management of cluster headache. Lancet Neurol 17:75-83, 2018

10. Láinez MJ, Guillamón E: Cluster headache and other TACs: pathophysiology and neurostimulation options. Headache

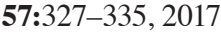

11. Leone M, Franzini A, Proietti Cecchini A, Bussone G: Success, failure, and putative mechanisms in hypothalamic stimulation for drug-resistant chronic cluster headache. Pain 154:89-94, 2013

12. Leone M, Proietti Cecchini A, Messina G, Franzini A: Longterm occipital nerve stimulation for drug-resistant chronic cluster headache. Cephalalgia 37:756-763, 2017

13. Magis D, Gérard P, Schoenen J: Invasive occipital nerve stimulation for refractory chronic cluster headache: what evolution at long-term? Strengths and weaknesses of the method. J Headache Pain 17:8, 2016

14. Magis D, Gerardy PY, Remacle JM, Schoenen J: Sustained effectiveness of occipital nerve stimulation in drug-resistant chronic cluster headache. Headache 51:1191-1201, 2011

15. Miller S, Watkins L, Matharu M: Predictors of response to occipital nerve stimulation in refractory chronic headache. Cephalalgia 38:1267-1275, 2018

16. Miller S, Watkins L, Matharu M: Treatment of intractable chronic cluster headache by occipital nerve stimulation: a cohort of 51 patients. Eur J Neurol 24:381-390, 2017

17. Mitsikostas DD, Edvinsson L, Jensen RH, Katsarava Z, Lampl C, Negro A, et al: Refractory chronic cluster headache: a consensus statement on clinical definition from the European Headache Federation. J Headache Pain 15:79, 2014

18. Mueller OM, Gaul C, Katsarava Z, Diener HC, Sure U, Gasser T: Occipital nerve stimulation for the treatment of chronic 
cluster headache-lessons learned from 18 months experience. Cent Eur Neurosurg 72:84-89, 2011

19. Salgado-López L, de Quintana-Schmidt C, Belvis Nieto R, Roig Arnall C, Rodríguez Rodriguez R, Álvarez Holzapfel MJ, et al: Efficacy of sphenopalatine ganglion radiofrequency in refractory chronic cluster headache. World Neurosurg 122:e262-e269, 2019

20. Seijo-Fernandez F, Saiz A, Santamarta E, Nader L, AlvarezVega MA, Lozano B, et al: Long-term results of deep brain stimulation of the mamillotegmental fasciculus in chronic cluster headache. Stereotact Funct Neurosurg 96:215-222, 2018

21. Tepper SJ, Stillman MJ: Cluster headache: potential options for medically refractory patients (when all else fails). Headache 53:1183-1190, 2013

22. Wilbrink LA, Teernstra OP, Haan J, van Zwet EW, Evers SM, Spincemaille GH, et al: Occipital nerve stimulation in medically intractable, chronic cluster headache. The ICON study: rationale and protocol of a randomised trial. Cephalalgia 33:1238-1247, 2013

\section{Disclosures}

The authors report no conflict of interest concerning the materials or methods used in this study or the findings specified in this paper.

\section{Author Contributions}

Acquisition of data: Aibar-Durán, Álvarez Holzapfel. Analysis and interpretation of data: Aibar-Durán, Molet Teixido. Drafting the article: Aibar-Durán. Critically revising the article: Rodríguez Rodríguez, Belvis Nieto, Roig Arnall. Reviewed submitted version of manuscript: Aibar-Durán. Statistical analysis: Aibar-Durán. Study supervision: Rodríguez Rodríguez, Molet Teixido.

\section{Correspondence}

Juan Ángel Aibar-Durán: Hospital de la Santa Creu i Sant Pau, Barcelona, Spain.jaibar@santpau.cat. 